\title{
Relatos de una tradición. \\ Sobre los artefactos sonoros de las cuadrillas de San Martín (una investigación transdisciplinar)
}

\author{
Diana Marcela Herrera Muete \\ Pilar Jovanna Holguín Tovar ${ }^{* * *}$
}

Recibido: febrero 12 de 2018

Evaluado: mayo 31 de 2018

Aceptado: julio 10 de 2018

\section{Resumen}

En este artículo se presenta una síntesis de los conceptos y metodología empleada en una investigación que tuvo como objeto de estudio los instrumentos musicales y artefactos sonoros utilizados en las cuadrillas de San Martín. El objetivo de este artículo es describir parte del proceso con el propósito de revelar la fundamentación desde marcos teórico- metodológicos interdisciplinares y difundir los hallazgos de esta expresión sociocultural. Al abordar la organología musical como herramienta de descripción y sistematización para la clasificación de instrumentos sonoros se observó la necesidad de estudiar marcos y herramientas metodológicas de otros campos de conocimiento. Entre ellos se encontraron la historia oral, la arqueomusicología y la fotografía. La metodología es de corte descriptivo y se presenta en tres etapas: la fundamentación teórica, la observación simple, la recopilación de memorias y material fotográfico; y finalmente, la presentación de los resultados obtenidos a través de la investigación.

Palabras clave: cuadrillas de San Martín, organología, artefactos sonoros, memoria histórica y música, instrumentos musicales colombianos.

Artículo de investigación. Producto de los proyectos: Re-encuentro con la esencia instrumental de las legendarias cuadrillas de San Martín de los Llanos, el proyecto Prácticas crítico interpretativas: aplicación del análisis hermenéutico de la Universidad Pedagógica y Tecnológica de Colombia y el proyecto de investigación participativo del Ministerio de Cultura y la Fundación TRIDHA, la exposición Cuadrillas Historia Viva de una Tradición. Citar como: Herrera, D y Holguín, P. (2018). Relatos de una tradición Sobre los artefactos sonoros de las cuadrillas de San Martín (una investigación transdisciplinar). Hallazgos, 15(30), 157-176. DOl: https://doi.org/10.15332/2422409X.4808

** Licenciada en Música de la Universidad Pedagógica y Tecnológica de Colombia. Contacto: elritosoy@gmail.com

*** Doctoranda de la Universidad Nacional de Rosario-Argentina. Docente de la Universidad Pedagógica y Tecnológica de Colombia. Contacto: pilar. holguin@uptc.edu.co 


\section{Tales of a tradition. \\ About the sound artifacts of the cuadrillas de San Martín (a transdisciplinary investigation)}

\begin{abstract}
This article presents a synthesis of the concepts and methodology used in an investigation that had as object of study the musical instruments and sound artifacts used in the San Martín cuadrillas. The objective of this article is to describe part of the process with the purpose of revealing the foundation from interdisciplinary theoretical-methodological frameworks and transmit results obtained about of this socio-cultural expression. When addressing musical organology as a description and systematization tool for the classification of sound instruments, the need to study frameworks and methodological tools from other fields of knowledge was observed. Among them were oral history, archeomusicology and photography. The methodology is descriptive and is presented in three phases: the theoretical basis, the simple observation, the collection of memories and photographic material and finally, the presentation of results obtained through the investigation.
\end{abstract}

Keywords: cuadrillas of San Martín, organology, sound artifacts, historical memory and music, colombian musical instruments.
Received: february 12, 2018

Evaluated: may 31,2018

Accepted: july 10, 2018 


\section{Histórias de uma tradição \\ Sobre os artefatos sonoros das cuadrillas de San Martín (uma investigação transdisciplinar)}

Received: february 12, 2018

Evaluated: may 31,2018

Accepted: july 10, 2018

\section{Resumo}

Este artigo apresenta uma síntese dos conceitos e metodologias utilizadas em uma investigação que teve como objeto de estudo os instrumentos musicais e artefatos sonoros utilizados nas quadrilhas de San Martín. O objetivo deste artigo é descrever parte dos processos com o objetivo de revelar os referenciais teórico-metodológicos interdisciplinares e disseminar os achados na observação dessa expressão sociocultural. Ao abordar a organologia musical como uma ferramenta de descrição e sistematização para a classificação de instrumentos sonoros, observou-se a necessidade de estudar os arcabouços e ferramentas metodológicas de outras áreas do conhecimento. Entre eles, citamos a história oral, a arqueomusicologia e a fotografia. A metodologia é de natureza descritiva e está apresentada em três etapas: fundamentação teórica, observação simples, coleta de memórias e material fotográfico e, finalmente, a apresentação dos resultados obtidos através da investigação.

Palavras-chave: quadrilhas de San Martín, organologia, artefatos sonoros, memória histórica e música, instrumentos musicais colombianos 


\section{INTRODUCCIÓN: EL CONTEXTO Y LA CUESTIÓN SOBRE LAS CUADRILLAS}

Las manifestaciones culturales revelan la historia y el actuar de una sociedad. Las personas se establecen como comunidad a partir de ideologías, estilos y formas de convivencia (Castillo, 2013). Las manifestaciones culturales son, por naturaleza o por definición, actividades públicas cuyas características radican en producir un acto comunicacional alrededor del cual, un grupo más o menos definido, se identifica (Pantoja 2012). Las expresiones culturales ancestrales, en su mayoría de tradición oral, pueden desaparecer debido a la poca documentación y divulgación que se realiza de éstas. Existen situaciones en las comunidades que transforman las manifestaciones culturales. Entre ellas se encuentran la falta de interés de las nuevas generaciones por conocer su historia o la necesidad de cambio de estas generaciones, motivada por procesos como la globalización o la hibridación cultural (García Canclini, 2004). Las expresiones de carácter tradicional requieren de la documentación para que su comunidad las conozca, valore y reconozca su evolución.

De acuerdo a lo anterior, surgió una investigación en torno a una de las expresiones culturales del municipio de San Martín de los Llanos - departamento del Meta-Colombia - denominada Las legendarias cuadrillas de San Martín. Ésta manifestación es una representación cultural que involucra una relación entre la tradición y la memoria, que está concebida y recreada a través del imaginario colectivo de los miembros de la región. San Martín de los Llanos se encuentra ubicado a $154 \mathrm{~km}$ de Bogotá - capital de Colombia-, sobre la vía al llano y en el centro del departamento del Meta. Es considerado uno de los municipios más antiguos del departamento del Meta, con 428 años de fundación y con una población aproximada de 21,511 habitantes, según el censo general de 2005. San Martín se integró a la provincia de Bogotá bajo el nombre del Cantón de San Martín, pero diez años después, los cantones fueron abolidos. San Martín y Casanare pasaron a formar parte de la administración de los Estados Unidos de Colombia, como territorios cedidos por Cundinamarca. En el año de 1869 San Martín pasa a ser territorio nacional y a considerarse como capital de este.

En el año de 1905 surge la intendencia nacional del Meta, que ubica a San Martín como municipio y a Villavicencio como capital del Meta - ubicación que mantiene hasta la fecha-. En 2002, y según el Acuerdo 038 de este mismo año, el municipio de San Martín pasa a formar parte del territorio de los Llanos Orientales y su nombre se cambia a San Martín de los Llanos. Las legendarias Cuadrillas de San Martín consisten en un espectáculo de arte escénico denominado juego o ballet ecuestre, en el cual se realiza una serie de diez juegos o actos que se presentan armónica y ordenadamente. En estos se demuestran las habilidades de los jinetes y la sincronización de sus coreografías. Los juegos se dividen así: dos son protocolarios, cuatro de guerra y cuatro de paz, nueve de estos a caballo y uno a pie.

Dentro del proceso de caracterización y representación de cada uno de los actores participantes de las cuadrillas, se utilizan algunos instrumentos musicales o artefactos sonoros que no han sido investigados. En el desarrollo de los juegos intervine el 
sonido como un elemento de ambientación. Es muy poco el registro que existe sobre las cuadrillas y específicamente en lo que se refiere a la expresión cultural es casi inexistente. Lo anterior fue el motivo para hacer esta investigación. Por ende, se busca contribuir con la documentación, clasificación y divulgación de los artefactos sonoros que se usan y se han usado dentro de las cuadrillas. En el proyecto se buscó responder a la pregunta: ¿qué artefactos sonoros e instrumentos musicales se utilizan en los juegos ecuestres y cuál es su historia?

Para dar respuesta al interrogante se propone describir parte del proceso investigativo realizado. Lo anterior con el fin de revelar la fundamentación basada en marcos teóricometodológicos interdisciplinares y difundir los hallazgos obtenidos. El artículo está estructurado en cuatro partes. En la primera se expone la historia de la cuadrillas. En la segunda se presentan conceptos como patrimonio y organología musical como base teórica del estudio. En la tercera se muestran nociones y algunas herramientas metodológicas usadas en el proyecto; y en la última parte se exponen resultados y conclusiones. A continuación se contextualizará detalladamente en qué consiste la tradición de las cuadrillas.

\section{LA HiSTORIA VIVA A \\ TRAVÉS DEL TIEMPO: REVISIÓN DE LA TEMÁTICA Y CONTEXTUALIZACIÓN}

Las guerras por el territorio y los conflictos interétnicos han estado presentes en el territorio de los llanos colombianos. No obstante, durante el proceso de colonización y repoblamiento de los llamados territorios ausentes, la historia de San Martín estuvo ligada a uno de los hechos de exterminio más grande que ha existido contra el pueblo indígena, especialmente contra Guahibos, Cuivas y Chirocas. Este hecho tan lamentable fue la llamada masacre de la Rubiera (Gómez y Gómez, 2010) en la cual, bajo la disculpa de una invitación a comer, los colonos atacaron y dispararon a todos los indígenas asistentes. Sobrevivieron dos personas, quienes dieron a conocer la historia. Esta masacre fue realizada bajo la "excusa" de que los colonos no sabían que matar indios fuera un hecho delictivo (Espinosa, 2007).

Los colonos, con su idea de sometimiento y expropiación, lograron amedrentar al pueblo indígena despojándolo de la mayoría de sus tierras. Por otro lado, los nativos indígenas, después de tal subordinación y al ser una minoría, se establecieron como trabajadores y peones a las órdenes de los colonos (Gómez y Gómez, 2010). Así pues, los principales momentos históricos que marcaron al territorio sanmartinero fueron: la llegada de los españoles, el ingreso de las misiones en el siglo xvir y la aniquilación casi total del pueblo indígena en el siglo XIX.

Durante el transcurso de las guerras y tras el establecimiento de los colonos a mediados del siglo XIX se desarrollaron, paralelamente, nuevas manifestaciones culturales. Durante la incursión de otras culturas y en el intercambio con estas, sobrevinieron hibridaciones y adaptaciones de costumbres que transformaron las identidades. Las tradiciones propias del territorio fueron reacomodándose frente a los nuevos sucesos. Esto se observa en la vaquería y el trabajo del llano, en la música, el folklor, la danza, la gastronomía y en las expresiones que 
representan la colonización en los juegos ecuestres de San Martín.

Las cuadrillas son una manifestación cultural que tiene 278 años de existencia y gira en torno a la relación tradición-memoria. Consisten en un espectáculo de arte escénico denominado juego o ballet ecuestre, único en el mundo, en el que se realizan una serie de diez juegos. Cada figura hace alusión a dos grandes momentos de los españoles o raza hispana. El primero es la guerra e invasión mora o árabe sobre la península Ibérica en el siglo viri y el segundo, la conquista del territorio americano en el siglo xv por la Corona Española. Las cuadrillas de San Martín datan del año 1735 y, según una de las versiones más divulgadas a cerca de su origen, son el legado de un sacerdote español llamado Gabino de Balboa. El clérigo, para evangelizar y divertir a los pobladores, hizo una recreación de guerras de época y de los juegos rituales realizados por los indígenas de la región. Estos se presentan cada doce lunas como agradecimiento a los dioses, aunque fueron readecuados a las costumbres y rituales de la Iglesia Católica y puestos en honor a su Santo Patrono San Martín de Tours (Junta Patronal de Cuadrillas, 2011). ${ }^{1}$

En su forma original, las cuadrillas están compuestas por 48 jinetes, divididos en los cuatro grupos o etnias participantes: doce árabes o moros, doce españoles o galanes, doce indios nativos o guahibos y doce negros africanos o cachaceros. Ellos son los

La Junta Patronal de Cuadrillas se elige por periodos de dos años, está conformada por un presidente -representante legal de las Cuadrillas-, vicepresidente, tesorero, fiscal y secretaria. Estos representantes son elegidos por votación en la asamblea general de cuadrillas, la cual está compuesta por la totalidad de los cuadrilleros, que son los votantes. actores escénicos principales y en cada grupo existen suplentes y coordinadores. En conjunto reciben el nombre de cuadrilleros y representan cada una de las cuatro razas que se encontraron durante el proceso de colonización y mestizaje. A partir de la creación del Plan Especial de Salvaguardia de las Cuadrillas (PES), se documentaron algunos posibles orígenes históricos que tomaron como fuente, la memoria de las personas que poseen información - transmitida por sus ancestros o por la participación directa - En la recopilación se incluyeron aspectos que representan la identidad cultural forjada en el imaginario colectivo de la población (Gómez y Gómez, 2010).

Las cuadrillas de San Martín de los Llanos se presentan cada año hacía el segundo domingo de cada noviembre, en la plaza de cuadrillas llamada Plaza de Cuadrillas Gabino de Balboa en honor a su posible creador. ${ }^{2}$ Los actores escénicos que conforman los cuatro grupos étnicos realizan un proceso de asimilación, caracterización y representación; es decir, cada una de estas etnias porta un atuendo especial con objetos distintivos, que finalmente buscan personificar cada una de las razas, según el imaginario de los sanmartineros. Se distingue la combinación entre la personificación de la raza por medio del uso del color, la indumentaria y cierta actitud corporal, que se identificó en las entrevistas realizadas durante la fase del trabajo de campo.

\footnotetext{
2 Si bien a través del tiempo, la creación de esta manifestación ha sido atribuida a un sacerdote llamado Gabino de Balboa, existe otra versión que menciona a un misionero religioso de apellido Acuña, Cuña o Cuhna. Hasta la fecha, ninguna ha sido corroborada en documentos 0 actas. Por el contrario, el origen se ha consolidado desde la oralidad e imaginario de la comunidad sanmartinera.
} 


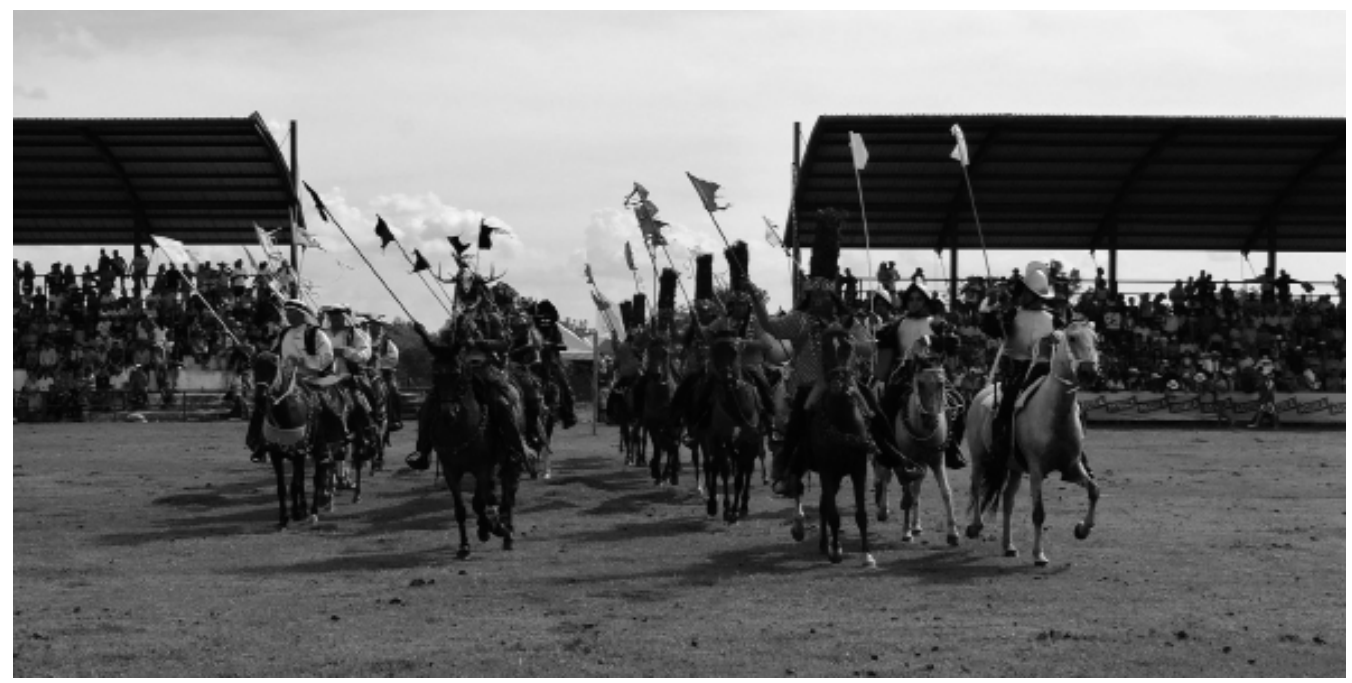

Figura 1. Fotografía de la representación de los cuatro grupos de las cuadrillas.

Fuente: semillero de investigación Artífice del Arte. UPTC: Tunja, Boyacá. 2012

Para la comunidad sanmartinera, las cuadrillas representan una parte importante de su cultura e identidad. Con más de 278 años de tradición, logran vincular directa e indirectamente a cuadrilleros, familiares, visitantes y comerciantes, entre otros. Durante la presentación de los juegos o actos de las cuadrillas, ${ }^{3}$ el público interactúa con los protagonistas o cuadrilleros, donde se percibe la identificación con cada uno los grupos que representa un grupo étnico. Se procura mantener la conformación de las cuadrillas a partir de la tradición familiar. Esta tradición es heredada de generación en generación por lazo sanguíneo, aunque en casos especiales se puede solicitar ser cuadrillero a la junta patronal del evento. Allí se debate y se examinan aspectos relevantes

3 Los juegos de las cuadrillas se representan en diez figuras. Estos quedaron registrados en la animación de Stop Motion que se realizó en la investigación conjunta con el Ministerio de Cultura y la Fundación TRIDHA, desde el Semillero de Investigación Participativa. como: ser buen jinete, ser sanmartinero, demostrar arraigo y deseo de preservación por la cultura sanmartinera, entre otras. En el caso de aprobarse la solicitud el candidato pasa a conformar la fila de suplentes de las cuadrillas.

A nivel nacional, esta actividad cultural se reconoció en el año 2002. Se estableció que las cuadrillas de San Martín son Patrimonio Cultural Inmaterial de la Nación (Ley 760 de 2002) y están protegidas desde 2010 por el Plan Especial de Salvaguardia (PES). ${ }^{4}$ A partir de la instauración de las leyes y el

4 El Ministerio de Cultura colombiano definió en 2009 que el Plan Especial de Cultura (PES) es un "acuerdo social y administrativo mediante el cual se establecen directrices, recomendaciones y acciones encaminadas a garantizar la salvaguardia del Patrimonio Cultural Inmaterial de las comunidades de la Nación. [...]. Es una herramienta de gestión que le ayuda a una comunidad o grupo social a conocer mejor, proteger, hacer visible y fomentar las manifestaciones de su cultura, es decir, a gestionar y salvaguardar su patrimonio". Disponible en http://www.mincultura.gov.co/areas/patrimonio/noticias/Paginas/2009-09-08_26664.aspx 
reconocimiento nacional se generaron diferentes proyectos de investigación que se enfocan en la cultura y la identidad. Entre estos se encuentra la creación del Semillero de Investigación Participativa de las Cuadrillas de San Martín en el año 2013. El semillero se vinculó al Ministerio de Cultura y la Fundación TRIDHA y generó algunos proyectos de grado.

Las investigaciones generaron un archivo en donde reposa material escrito - textos, libros, artículos, ponencias- y material audiovisual -audios de entrevistas, fotografías, videos, panfletos, entre otros-. Por medio de esta recopilación se socializó a la comunidad los documentos y se reconoció la gran cantidad de fuentes vivas que componen la historia oral de esta expresión cultural. Con la información obtenida se pretende seguir revisando el origen, desarrollo y evolución de esta tradición. Aún hay material que está oculto en las casas familiares de quienes participaron o participan en el evento y sería pertinente conocerlo para que no desaparezca. A continuación se presenta la fundamentación teórica en la que se basó este trabajo.

\section{Capital cultural y ORGANOLOGÍA MUSICAL: ALGUNOS CONCEPTOS SOBRE EL TEMA}

Al elegir como objeto de estudio un elemento que hace parte de una actividad que fue declarada patrimonio cultural inmaterial de las comunidades de la nación, es necesario revisar el origen y el concepto de patrimonio. En la indagación se observó que éste tiene relación con una construcción sociopolítica de los Estados nacionales, específicamente lo relacionado con la identidad. Lo anterior sugiere que la patrimonialización se relaciona con una ideología nacionalista que concibe la indisolubilidad entre Estado - lo político-económico- y la nación - las expresiones de los grupos humanos-. El nacionalismo, en América Latina, es una cuestión política que pretende generar un sentido de pertenencia para la burguesía y la clase media (Madrid A. , 2010). Éste se convierte en un instrumento híbrido entre lo propio y el cosmopolitismo que genera colectividades inventadas, siempre en relación con lo europeo (Martínez F. , 2001).

\section{Nacionalismo y patrimonio}

La nación es como una comunidad política imaginada, donde sus miembros se identifican como semejantes aunque no se conozcan entre sí. Está limitada debido a sus fronteras que marcan la separación de otras naciones. Es soberana por su adhesión al ideal independentista de la Ilustración europea (Benedict, citado en Mendivil, 2016). “El Estado-Nación se ha empeñado en instruir a sus hijos en el amor incondicional a la patria" (2016, p. 92); “El nacionalismo sería, en todo caso, una 'religión científica' o una 'ciencia religiosa' o, al menos en sus inicios cumpliría esa función" (Faraldo, 2001, p. 943). De acuerdo a lo anterior, se institucionalizaron y se desarrollaron las ciencias sociales - historia, sociología, geografía, entre otras-. El nacionalismo cultural, según Turino, es el trabajo semiótico que utilizan las prácticas artísticas para representar, crear y distinguir a la nación (citado en Mendivil, 2016).

El concepto de patrimonio cultural concuerda con el marco ideológico presentado anteriormente. El reconocimiento de patrimonio 
cultural surge en la UnEsCo para ser aplicado en la conservación de los monumentos arquitectónicos. A principios de los años noventa el concepto se amplía a patrimonio cultural intangible y de esta forma se incluye la salvaguardia de las tradiciones culturales inmateriales de los grupos humanos. El alcance del concepto incluyó a la música.

Las consecuencias no siempre fueron positivas, pues más temprano que tarde los estados descubrieron el potencial nacionalista que ofrecía la idea de patrimonio. [...] La patrimonialización suele permitir al Estado reclamar un derecho de propiedad sobre las expresiones musicales, lo que las convierte en un instrumento de manipulación política. (Mendivil, 2016, p. 106).

En este punto interviene otro concepto, el de autenticidad. Esto debido a que, políticamente, se debe salvaguardar lo auténtico. La conservación de las prácticas y la transmisión generacional están sujetas a características que fueron establecidas por las élites y por la academia. "Las medidas destinadas a conservar, salvaguardar y proteger ciertas prácticas culturales llevan a congelarlas" (Melo Ángel, 2013, p. 20). Según esto, las expresiones culturales deben mantenerse invariables para que sigan siendo auténticas. Melo Ángel propone que "la creación de inventarios no solo es la función de la salvaguardia. Debemos empezar a pensar los problemas ligados al desarrollo de las comunidades" (p. 22).

Esto implica replantear el enfoque de investigaciones de este tipo aunque los objetos de estudio sean muy delimitados como en este caso- - Dado que el proyecto buscó la clasificación y conocimiento de instrumentos sonoros usados en las cuadrillas fue necesario indagar sobre la organología. En las búsquedas realizadas se halló que dentro del conocimiento específico disciplinar musical se creó un área dedicada a la organización y sistematización de los instrumentos musicales. Las categorías propuestas provienen de los ámbitos de estudio de la música centroeuropea desde 1880 aproximadamente. La disciplina que surgió se llamó organología y para algunos estudiosos como Gétreau, Nettl, Rivas, Kunst, Curt Sachs y Eric Hornbostel, es el estudio científico realizado sobre los instrumentos musicales, con el fin de conocerlos y comprenderlos.

\section{La organología y el planteamiento de una organología social}

Con el surgimiento de la etnografía y la musicología comparada, Curt Sachs y Erik Von Hornbostel, desarrollaron el texto Systematik der Musikinstrumente en 1914. Tomaron como referencia el sistema de Mahillon y propusieron una metodología que permitió incorporar aspectos nuevos como cambiar el grupo de autófonos por el de idiófonos -idio: propio-. En el año de 1914, cuando este sistema de clasificación se presentó, se concluyó que la clasificación mostraba un modelo más sencillo, reconocible y con espacio para la inclusión de una infinidad de instrumentos (Vega, 1946).

Curt Sachs y Erick Von Hornbostel adoptaron, además, el sistema de numeración de Dewey, lo que permitió incrementar la subdivisión de cada clasificación, partiendo de las cuatro categorías principales: idiófonos, membranófonos, cordófonos y aerófonos. Estas subdivisiones funcionaron por medio de adiciones numéricas, se agregaron 
materiales y distinciones especiales dependiendo de la naturaleza del cuerpo del instrumento. Se obtuvo una cobertura casi total de los artefactos sonoros, no solo europeos $\mathrm{u}$ occidentales, sino toda clase de artefactos que tuviesen sonido. Esto permitió incluir los artefactos sonoros hallados en excavaciones, comunidades primitivas y aquellos que surgieron de experimentos sonoros.

Según Pérez de Arce y Gili (2013), el sistema de clasificación más usado en la organología es el de Curt Sachs y Erich Hornbostel (SH). Este sistema es ampliamente aceptado en América Latina, hecho que generó traducciones al inglés y al español. Quien realizó esta tarea en el idioma español fue Carlos Vega - argentino-. Él manifestó algunos problemas que tuvo con las nomenclaturas debido a las diferencias idiomáticas. Con la traducción realizada por Vega, otros investigadores usaron el sistema SH. "Se pueden destacar los trabajos de Fernando Ortiz (1952) en Cuba, Isabel Aretz (1967) en Venezuela, Bolaños y otros (1978) en Perú, Gudemos (1988) en Argentina y Ernesto Cavour (1994) en Bolivia, entre otros" (2013, p. 48)

El sistema de clasificación $\mathrm{SH}$, a pesar de ser el más utilizado, ha sido criticado fuertemente (Gétreau, 2009) debido a algunos vacíos que se presentan cuando se encuentran instrumentos similares. La crítica surge porque no permite incorporar los rasgos culturales de donde proviene el instrumento o artefacto. La clasificación de los instrumentos musicales debe corresponder con la metodología propuesta en cada caso particular y se deben considerar las concepciones y usos que le otorga la cultura al instrumento. Este tipo de perspectiva corresponde más con una intención de enfocar la investigación en cuanto a la organización del material organológico. Esto se sugiere para evitar las clasificaciones taxonómicas (Pérez de Arce y Gili, 2013).

Las ideas anteriores deben estar presentes durante el desarrollo de la investigación debido a que el aislamiento de los objetos de estudio puede resultar desfavorable. Mendivil expone que la organología separa los instrumentos de su contexto para mostrarlos como piezas de museo (2016). Las colecciones de instrumentos están fuera de lugar ya que están deshumanizados (Dawe, 2001; Bates, 2012). "[Los instrumentos], como cultura, material, contienen no solo su forma, sino también sus valores y creencias, saberes tecnológicos y estéticos, pudiendo referir por consiguiente historias sobre quienes los construyen, los ejecutan y los escuchan" (Mendivil, 2016, p. 154). Esto implica que los instrumentos, aparte de generar sonido se convierten en productos culturales que evidencian la interrelación con sus ejecutantes dentro de una red social (Bates, 2012).

Rancier sugirió que los instrumentos musicales se convierten en archivos, pues con la reproducción de los sonidos y sus repertorios, guardan implícitamente información histórica (citado en Mendivil 2016). El estudio de las músicas del mundo - junto con sus componentes - sirve para comprender significaciones y estructuras que las personas le atribuyen (Pelinsky, 2000).

Bates dijo: los significados culturales de los instrumentos no son estáticos y al transformarse desarrollan biografías. [...] Los saberes que encierran los instrumentos solo pueden ser extraídos al observar o inquirir su relación con los individuos que los fabrican, ejecutan y escuchan. Debemos estudiarlos 
como herramientas para la producción y reproducción de la cultura y no como objetos inanimados, independientes de las vicisitudes de las sociedades en las cuales existen. (Mendivil, 2016, pp. 157-159).

Investigaciones que incluyan la perspectiva anterior permitirán registrar para comprender las transformaciones de las expresiones culturales. La documentación puede hacer visibles estos cambios para pensar en sistemas dinámicos en lugar de convertirlos en artefactos intangibles (Melo Ángel, 2013). Esto implica un reto en trabajos investigativos locales. De algún modo la música o las expresiones culturales periféricas cuestionan las demandas universalistas. Rebaten discursos estéticos eurocentristas y evidencian la falibilidad de las herramientas usadas para describir las expresiones musicales. Lo anterior se debe a que quedan fuera de los sistemas de valores eurocéntricos (Madrid, 2008). Las herramientas analíticas usadas para estas expresiones conllevan implicaciones colonialistas. De acuerdo a lo anterior, a continuación se expondrán los conceptos y técnicas que se aplicaron en esta investigación.

\section{Perspectiva metodológica PARA UNA INVESTIGACIÓN INTERDISCIPLINAR}

Existe poco conocimiento sobre las técnicas desarrolladas para el análisis, la sistematización y la documentación de instrumentos musicales (Hortelano, 2008). La etnomusicología como un área asociada al trabajo organológico tiene como objeto de estudio la música tradicional y los instrumentos musicales de las culturas. Esto implica la búsqueda de diferentes conceptos de disciplinas afines que permitan encontrar postulados y herramientas para la recopilación y sistematización de la información. La relación que se establece entre diferentes disciplinas, tanto directa como indirecta, con los sistemas de clasificación organológica es indispensable para evitar aislar los instrumentos o artefactos musicales del contexto y su comunidad. Por lo anterior, para el desarrollo del proyecto se tuvo en cuenta conceptos y técnicas de la historia oral, específicamente lo relacionado con la memoria. En segundo lugar, se incluyeron pautas para el análisis fotográfico y algunos procedimientos de la arqueomusicología.

\section{Historia oral y memoria}

En el periodo de las guerras mundiales del siglo $\mathrm{xx}$, los intelectuales se interesaron en nuevas temáticas y en la aplicación de metodologías contrastantes para explicar la realidad histórica. La escuela de Frankfurt cuestionó el positivismo y la idea de progreso. Esto conllevó al abordaje de temas relacionados con la memoria, la tradición y la transmisión de la memoria colectiva. Nora, Le Goff y Ricoeur iniciaron los estudios sobre el concepto de memoria histórica y esto contribuyó a la divulgación de algunas ${ }^{5}$ (Rueda Arenas, 2013).

El término memoria en el marco de la disciplina histórica se relaciona con la historia oral. Ésta se consideró como propia de las sociedades ágrafas que por medio de la interacción y la tradición generan transmisión de información (Rueda Arenas, 2013). "Para Aleka Boutzouvi la historia oral atañe

5 En un principio fueron las memorias de las víctimas de la guerra y de los gobiernos represivos. 
a grupos de individuos que pertenecen a categorías sociales concretas y comparten características étnicas, raciales, ocupacionales o de otra índole, pero cuyas vidas no figuran en las fuentes escritas" (Barela, Miguez y García Conde, 2004, p. 14). Para Thompson es "La interpretación de la historia, de las sociedades y las culturas en proceso de cambio a través de la escucha y registro de las memorias y experiencia de sus protagonistas" (Thompson, 2003 y 2004). ${ }^{6}$

Las características de la historia oral son la particularidad, la subjetividad y la memoria. La memoria brinda un criterio de identidad personal y es, a su vez, un fenómeno colectivo porque es vívido de forma social. Cualquier recuerdo hace parte de la memoria colectiva de los grupos a los que perteneció el individuo y son parte de la referencia sociohistórica. El recuerdo llega con la ayuda de otros, esto significa que es individual pero se puede construir colectivamente. La memoria está mediada por el lenguaje, el espacio y el tiempo. "Mediante la memoria el sujeto transita del presente al pasado, hace referencia a que siendo esto una paradoja la memoria le da continuidad al ser humano en el tiempo" (Rueda Arenas, 2013, p. 21).

“La historia oral apela a la memoria del sujeto para hacer historia a partir del relato de sus recuerdos y la fuente es el testimonio que el individuo da dentro del contexto de una entrevista" (Barela, Miguez y García Conde, 2004, p. 14). Las entrevistas en la historia oral difieren de las realizadas en otras áreas en algunos aspectos. El cambio ocurre en la

6 Este autor considera que no se le puede concebir como método fijo o subdisciplina separada. Para él es un método interdisciplinar. Las dos últimas definiciones se consideraron pertinentes para el contexto elegido en esta investigación. perspectiva de lo que se escucha, lo que se busca y lo que se interpreta. Se apela al recuerdo del informante y durante la reconstrucción del recuerdo se genera la memoria. Como resultado surge un documento que está mediado por los siguientes factores: la fuente - elección correcta del informante $-{ }^{7}$ un conocimiento preliminar sobre lo que se va a investigar, los temas que serán abordados, la formulación de las preguntas y el "estar atento no sólo a las respuestas sino también a los silencios" (p. 19). En el desarrollo de este proyecto se aplicaron entrevistas individuales semiestructuradas. A continuación se expone lo relacionado con el análisis fotográfico.

\section{La fotografía: un agente reconstructor de la memoria}

Reyero en su artículo "La fotografía etnográfica como soporte o disparador de memoria: una experiencia de la mirada" (2007) expresa la importancia que ha cobrado la imagen a través del tiempo como objeto en la búsqueda de recuerdos en el sujeto. El autor presenta la imagen fotográfica como una producción cultural, en la que se puede leer y analizar una retórica implícita, no obstante, admite que existen ciertas variables en sus perspectivas de lectura. La fotografía y los archivos fotográficos ayudan a la investigación de las ciencias y las artes a comprender e interpretar objetos, sujetos o entornos que sin este registro se perderían.

En el aspecto cultural, la fotografía o la imagen fija ayudan a relacionar o a interpretar objetos, posturas o colores que se

7 Sobre la "elección correcta del informante" se refiere, según Grele, a que ese sujeto tipifica ciertos procesos históricos que son aquellos sobre los que indaga el entrevistador (Barela, Miguez y García Conde, 2004). 
convierten en signos icónicos que se pueden interpretar desde el imaginario colectivo y el contexto de donde surgió el signo (Hall 1997). Se puede afirmar que la representación fotográfica y más exactamente la investigación que se logra hacer a partir de la imagen como medio de reconstrucción de memoria, en la mayoría de los casos, se hace desde ciertos condicionamientos. Estos condicionamientos suelen ser generados por el sujeto a partir de su formación intelectual, académica, experiencial y su acercamiento al acontecimiento y al simple hecho condicionante intencional de lo que desea encontrar (Lara 2005).

La metodología de Erwin Panofsky (1994) indica cómo analizar las imágenes y generar su significado a través de tres niveles de profundización. Para realizar el análisis propone tres tópicos en la imagen que son: 1) la forma, aquello que es evidente, 2) la idea que indica la temática de la que trata la imagen, y 3) el contenido. A partir de estos tópicos se generan tres etapas, la primera llamada preiconográfica que permite al analista reconocer objetos y hechos que son de fácil comprensión debido a su experiencia práctica. La segunda etapa es el nivel iconográfico, en el que se busca el significado secundario a partir de las alegorías o historias que se combinan con los significados primarios que brinda la primera etapa. En esta etapa recomienda el dominio de las fuentes secundarias que permitan reconocer las condiciones históricas o conceptos expresados por los objetos y las acciones plasmadas. El tercer nivel o iconológico busca el significado intrínseco y los valores simbólicos de la imagen.

En el proyecto de investigación sobre las Cuadrillas de San Martín se tuvo en cuenta solamente la primera y la segunda etapa propuesta por Panofsky debido a que ésta fue una investigación descriptiva. A continuación se exponen dos etapas, provenientes de la arqueomusicología, que se consideraron pertinentes durante y después de la investigación.

\section{Algunos tópicos de la arqueomusicología: investigación para la comunidad}

Hortelano (2013) expone que Homo Lechner (1989) sistematizó las pautas de las investigaciones centradas en la arqueomusicología a partir de tres momentos, el primero correspondiente a los materiales y el segundo con las actividades. Al primer momento lo llamó "primer triángulo de oro en la investigación" y se relaciona con los materiales de pesquisa: el texto, el objeto y la imagen. El siguiente momento se llamó "segundo triángulo de oro" y son las actividades como el reconstruir, documentar e informar. En este segundo triángulo convergen especialidades que complementan el estudio como la organología, etnomusicología, historia y sociología, entre otras.

El documentar consiste en seguir cuatro líneas de trabajo como: la música en sí, los instrumentos hallados en contextos arqueológicos, las representaciones instrumentales, otras manifestaciones musicales y los textos que mencionan la práctica musical. A partir de lo anterior se puede inferir que la organología musical articulada con otras áreas permite el diseño o complemento de sistemas de clasificación, identificación y organización de cada instrumento o artefacto sonoro estudiado. Este procedimiento se lleva a cabo teniendo en cuenta las características físicas, morfológicas o el rol que 
cumplen los artefactos sonoros dentro de la comunidad investigada (Greteau 2009, Nettl 2011, Kunst 1959). Esto se aplicó, de forma incipiente, en la sistematización de la información de los artefactos.

La divulgación de los hallazgos se convierte en un factor fundamental para visibilizar los resultados. En este caso, el proceso de socialización de los instrumentos musicales en la comunidad, además de contribuir al campo de conocimiento, evidencia la importancia de los informantes y la de aquellos que contribuyeron con el préstamo de sus fotografías. Luego de la exposición de algunas de las técnicas que sirvieron al proyecto, a continuación se presenta una síntesis de los resultados.

\section{SOBRE CUADRILLEROS Y ARTEFACTOS SONOROS: ALGUNOS RESULTADOS}

El objetivo del proyecto de investigación fue caracterizar los artefactos e instrumentos sonoros que se han utilizado en los juegos ecuestres de las cuadrillas de San Martín por medio de la recopilación información proveniente de fuentes vivas y visuales para conocer su historia, construcción e interpretación. Uno de los objetivos específicos fue diseñar fichas para registrar la información recolectada con el fin de conocer los materiales utilizados en la fabricación, el funcionamiento de los mismos y su función dentro del evento. Durante este proceso se diferenciaron dos momentos.

El primero fue la observación simple o no estructurada que permitió la descripción de los grupos étnicos. Moros o árabes tienen un artefacto sonoro que es común para los cuatro equipos: la sonaja. Fabricada con semillas nativas llamadas cucarachos, son entretejidas en cuerdas del color representativo de cada grupo y colocadas como pecheras o en las patas de los caballos. El grupo de galanes o españoles también usa solo sonajas que colocan en los caballos. Guahibos o indígenas nativos usan más artefactos sonoros que son parte de su personificación - caracterizados por ser bulliciosos, alegres y agiles jinetes-. Esta cuadrilla representa a los indígenas Achagüas asentados en el territorio de San Martín de los Llanos. Los instrumentos musicales son el cacho o trompeta natural que se utiliza para hacer los llamados, el carrizo, los rondadores, las armónicas, los pitos, silbatos y sonajas. Estas últimas se encuentran amarradas en los tobillos y manos de los actores, como parte de su indumentaria y también en los caballos. Cachaceros o negros africanos usan el cacho y sonajas. En el análisis fotográfico, se descubrió que anteriormente usaron diferentes artefactos sonoros. Fueron descubiertos: la zambumbia - guadua con cuerdas a modo de instrumento de percusión, para hacer la sonoridad de un bajo marcante-, sonajas de conchas o semillas o dientes, carrizos, carracas de burro o caballo, furrucos y silbatos (Herrera Muete, 2014).

El segundo momento se dio por la necesidad de conocer a profundidad las cuadrillas. En una entrevista realizada al historiador de este municipio se obtuvieron algunos detalles sobre personas representativas que moran en San Martín. Son representativas por su experiencia en la fabricación de instrumentos artesanales, realizados con semillas, guaduas y cuernos. Conocen historias y el uso de estos en ocasiones especiales y su duración. Algunos artefactos, generalmente, 
eran destruidos durante su uso; por tal razón algunos se dejaron de utilizar en la actualidad. Lo anterior evidenció la necesidad de registrar los recuerdos de estas personas.

\section{Sujetos y materiales}

Se realizaron varias entrevistas semiestructuradas a integrantes y exintegrantes de las cuadrillas. El rango de edades fue de 23 hasta 71 años. Se sistematizaron, de forma preliminar, treinta entrevistas. Las preguntas se clasificaron en tres secciones. La primera relacionada con los datos personales del informante - edad, profesión, grupo al que pertenece, tiempo de participación- - La segunda se enfocó a la descripción de las cuadrillas - vestuario, historia que conoce, instrumentos que porta e instrumentos que conoció en el pasado-; y la tercera estuvo enfocada en el significado de participar en las cuadrillas.
Posteriormente, con la información recopilada en las entrevistas, se procedió a la recopilación de 200 fotografías de las cuales 56 mostraban instrumentos musicales en ellas.

\section{Procedimiento}

La discriminación fotográfica se realizó por medio de una ficha de inscripción y registro (figura 2). A cada fotografía se le asignó un número para codificarla.

Durante el proceso de discriminación fotográfica fue necesario realizar un análisis minucioso de cada fotografía. Los análisis se hicieron junto con el antropólogo Carlos Cárdenas, el coordinador de la cuadrilla de los Guahibos Mateo Carrillo y Pedro Camilo Saavedra, quienes por medio de la proyección a gran escala de las imágenes resaltaron cada uno de los artefactos observados.

\begin{tabular}{l|c|c|c|c|c}
\hline Fotografía $\mathrm{N}^{0}$ & $\begin{array}{c}\text { Cantidad de } \\
\text { instrumentos }\end{array}$ & $\begin{array}{c}\text { Clasificación del } \\
\text { instrumento }\end{array}$ & $\begin{array}{c}\text { Nombre genérico de/ } \\
\text { los instrumentos }\end{array}$ & $\begin{array}{c}\text { Grupo } \\
\text { portador }\end{array}$ & $\begin{array}{c}\text { Lugar de } \\
\text { hallazgo }\end{array}$ \\
\hline
\end{tabular}

Figura 2. Ficha de sistematización y documentación del hallazgo de instrumentos en fotografías dentro de la manifestación de cuadrillas.

Fuente: Herrera Muete (2014).
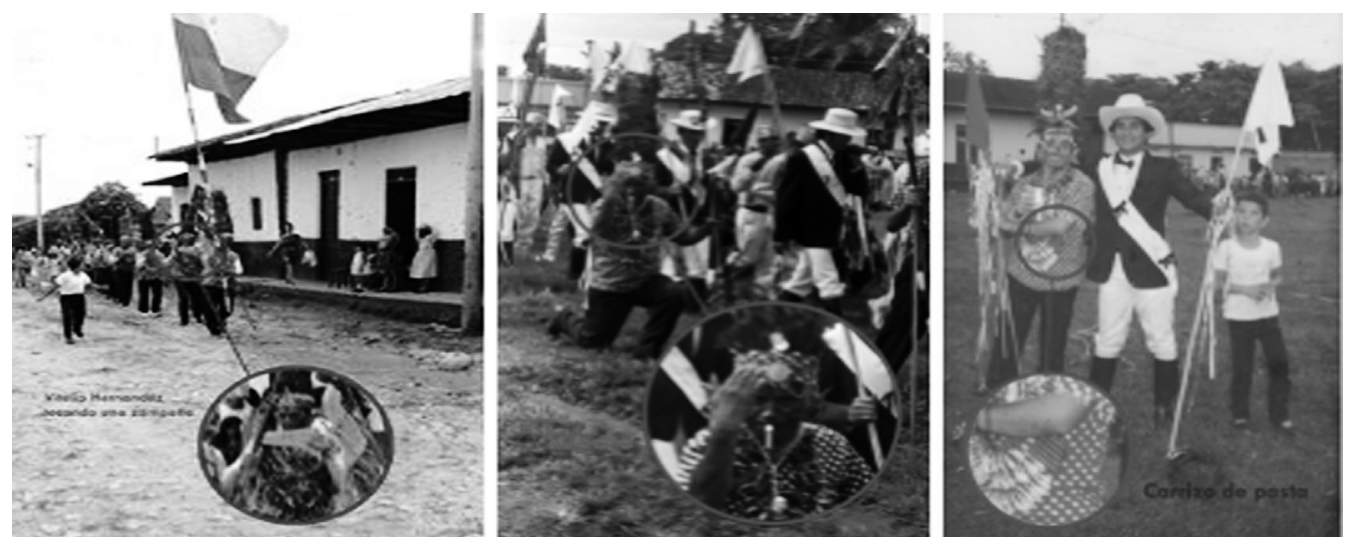

Figura 3. Captura de detalles de instrumentos o artefactos sonoros para el análisis de fotografías tomadas de archivos personales y del PES.

Fuente: Herrera Muete (2014). 


\begin{tabular}{|c|c|}
\hline $\begin{array}{c}\text { NOMBRE GENÉRICO } \\
\text { DEL ARTEFACTO SONORO: }\end{array}$ & FOTO \\
\hline Descripción dentro de la oralidad de la comunidad: & \\
\hline Clasificación: & \\
\hline Material: & \\
\hline Diámetro: & \\
\hline Fabricación: & \\
\hline
\end{tabular}

Figura 4. Ficha de sistematización y documentación individual de los instrumentos musicales hallados en las fotografías.

Fuente: Herrera Muete (2014)

\begin{tabular}{l|l}
\hline Nombre del artefacto: & Dimensiones: \\
\hline Clasificación instrumentral: & \\
\hline Materiales: & \\
\hline Fabricación: & \\
\hline & \\
\hline Descripción: & Interpretación: \\
\cline { 2 - 2 } & Uso dentro del juego: \\
\hline Fotografías: & \\
\hline Historia y origen: & \\
\hline & \\
\hline
\end{tabular}

Figura 5. Ficha de clasificación de los instrumentos.

Fuente: Herrera Muete (2014)

Con fotografías donde aparecen instrumentos musicales se realizó el registro y clasificación de cada uno de los artefactos sonoros. Lo anterior siguiendo la metodología de Curt Sachs y Erick Hornbostel. La sistematización se hizo por medio de las fichas que se presentan en la figura 4 para posteriormente ser sistematizados en una ficha (figura 5).

\section{Resultados}

A partir de la descripción de fotografías familiares antiguas ${ }^{8}$ y los relatos de sus due-

8 Entre las fotografías examinadas se encuentran: la recopilación de Plan Especial de Salvaguardia (PES), el registro audiovisual realizado con el semillero de investigación Artífice del Arte (Escuela ños se obtuvo información sobre los diferentes artefactos empleados antiguamente en Las Cuadrillas de San Martín. Se pudo establecer que algunos instrumentos sonoros ya no se usan en la actualidad. Durante el análisis fotográfico se encontraron tres tipos de sonajeros -idiófonos sacudidos, percutidos sacudidos y semisacudidosfabricados con una variedad de materiales naturales y sintéticos tales como semillas, huesos, caracoles, topes de cachos, cascos y caparazones de animales, monedas y metales, entre otros.

de Artes, UPTC) en el año 2001. Esta compilación fue obtenida en visitas a casas de los cuadrilleros entrevistados y en algunos de los registros realizados durante esta investigación, en el marco del proyecto investigativo del Ministerio de Cultura y Patrimonio en 2013. 
Dentro de los instrumentos de embocadura con altura determinada e indeterminada, se observaron una gran variedad de instrumentos andinos entre los que se encontraron aerófonos como zampoñas, la zicura, rondadores y carrizos de diferentes tamaños y materiales. Se encontraron pitos y silbatos de materiales sintéticos - como pitos de piñata - y de materiales naturales como las trompas de cacho o cuerno vacuno, la ocarina de totumo y los silbatos de huesos. Se halló la armónica o dulzaina que fue incluida por el grupo de los Guahibos. Se observó un instrumento de percusión de doble membrana.

Aunque los portadores de los objetos sonoros informaron que fueron usados como parte de su atuendo y performance dentro del juego, no se descarta la interpretación de cuatro instrumentos musicales más. Son la zambumbia de cuadrillas, la carraca, el furruco y la hoja con los que se interpretó, en el pasado, el joropo sabanero. De estos no se cuenta con mayor evidencia fotográfica. Según los cuadrilleros, los artefactos sonoros existentes son herencia de sus padres o cuadrilleros retirados, de quienes tomaron o recibieron su "puesto".. "

Las fichas de sistematización propuestas en este proyecto buscaron ser una guía para la clasificación de los artefactos sonoros como parte de una expresión cultural. La intención de la categorización fue la de presentar información de la clasificación organológica para explicitar, paralelamente, cualidades propias de los artefactos encontrados. Esto incluye la información de las fuentes vivas

9 Las Cuadrillas de San Martín de los Llanos, son una tradición familiar y los puestos son heredados de padres a hijos o en casos especiales son solicitados a la JPC por méritos. Las mujeres no participan de los juegos, por ser una manifestación patriarcal de carácter religioso y católico. como la ideología étnica asociada al accesorio, uso en el juego e interpretación según el caso. ${ }^{10}$ Desde esta perspectiva se buscó la manera más adecuada, incluyente y práctica para la difusión en la comunidad.

El modelo de clasificación propuesto está abierto para ser evaluado o para la discusión, mejoramiento o la inclusión de algunos aspectos, que en su momento no se tuvieron en cuenta. Esto está en concordancia con la fundamentación presentada en este texto: los instrumentos o artefactos sonoros hacen parte de una red social que no se mantiene estática. Eso implica que en las investigaciones de artefactos sonoros es necesario realizar adaptaciones a los sistemas de clasificación elegidos. Lo anterior debido a que las comunidades investigadas son diferentes o se transforman y, por ende, su propia diversidad obligará, en algunos casos, a modificar marcos y metodologías para el estudio de sus objetos musicales.

\section{Conclusiones}

Con la clasificación de los artefactos sonoros se logró determinar, en un primer acercamiento, las características físicas, interpretativas e históricas de doce artefactos e instrumentos y se hizo una muestra a la comunidad de San Martín de los Llanos. Los

10 Ejemplo del uso del cacho en el juego: "el cacho representa un símbolo de poder y liderazgo, ya que cuando es interpretado en las cuadrillas, todos los grupos que la conforman deben acudir a su llamado, ya sea en la alborada inaugural, después de organizados y vestidos. En cada una de las rancherías o cuando los Guahibos se reúnen al lado de la plazuela en señal de que los cuadrilleros, en su totalidad, deberán estar presentes para el desfile inicial. Según Gonzáles (cuadrillero titular, 2013), el cacho -lo usamos cuando saliamos de la maloca, para agruparnos y cuando jugamos, también lo hacemos sonar-. Además es el instrumento musical que por obligación debe interpretar un cuadrillero Guahibo" (Herrera Muete, 2014, p. 68). 
cuadrilleros fueron una fuente viva muy importante para el desarrollo del proyecto debido a su conocimiento. Aportaron en la compilación fotográfica y en la búsqueda de excuadrilleros que usaron elementos sonoros como parte de la indumentaria y ambientación de los juegos. Por otro lado, se logró conformar un archivo fotográfico que se entregó a la Junta Patronal de Cuadrillas.

Se halló, además, que la relación fotografía-recuerdo, fue uno de los factores que más aportó información en el hallazgo de artefactos sonoros. En el análisis de fotografías se confirmó la existencia de los instrumentos musicales asociados a los relatos. Esto evidencia parte de la transmisión de la historia de esta expresión cultural. Específicamente, en lo relacionado con la construcción e interpretación de los artefactos e instrumentos que pasaron de una generación a otra.

Se observó que el uso de los objetos sonoros es diferente en cada uno de los grupos, étnicos representados. En la trayectoria que realiza la cuadrilla de los Guahibos y los cachaceros haceros - raíces ancestrales con componentes indígena y africano- se observa un mayor número de instrumentos sonoros que en la cuadrilla de los árabes o moros y españoles o galanes. Dentro los instrumentos musicales artesanales se observó que, con los procesos invasión o migración, se adoptaron instrumentos de otras regiones. La mayoría de artefactos sonoros son accesorios complementarios para la caracterización de un personaje étnico dentro del juego, pero son relevantes al momento de ser interpretados por el refuerzo que brindan a la caracterización.

Las cuadrillas de San Martín evidencian una ideología sobre el mestizaje. En la representación de estos grupos étnicos moros o árabes, españoles o galanes, Guahibos indios nativos y cachaceros o negros africanos - se observa la mezcla de diferentes artefactos o instrumentos musicales, la creación de atuendos y accesorios. Las caracterizaciones surgen de acuerdo a unos imaginarios preestablecidos que deben ser investigados a profundidad en otros proyectos.

La divulgación de los hallazgos a la comunidad hizo evidente y necesaria la creación de una institución que albergue los archivos producto de investigaciones como esta. Se pudo constatar que el método más empleado para mantener la historia de las cuadrillas fue el de la transmisión oral. Paralelamente a este proceso, se observó que con las muestras se generó interacción con la comunidad de la región y esto puede generar vínculos afectivos que influirán en una mayor apropiación de este evento.

En lo relacionado con el impacto social, este proyecto permitió compartir las memorias de algunos exintegrantes de las cuadrillas o actores retirados, que por su avanzada edad o por su retiro de la actividad en las cuadrillas, no habían sido tenidos en cuenta para la difusión pública de sus conocimientos. El diálogo con ellos permitió un intercambio para conocer sus relatos a través de las imágenes y conocer sus puntos de vista acerca de la utilización y fabricación de los objetos sonoros empleados cuando eran miembros de las cuadrillas. Al terminar el proceso se realizó una exposición fotográfica que generó impacto debido al reconocimiento del legado instrumental hallado en fotografías. Esta primera exposición de imágenes presentó la fabricación, uso y recopilación de 
ciertos instrumentos musicales de quienes mostraron sus fotografías. ${ }^{11}$

Se destaca que, luego de 278 años de tradición de las legendarias cuadrillas de San Martín de los Llanos, por primera vez los cuadrilleros y habitantes del municipio observaron detalladamente los accesorios que portaban cada uno de los actores principales. Esta integración de la comunidad al proyecto generó una reconstrucción histórica colectiva que permitió hallar instrumentos musicales y artefactos sonoros desconocidos u olvidados. Durante las entrevistas previas a la observación fotográfica, la mayoría de cuadrilleros no tenían presente el uso de objetos sonoros como complemento de su indumentaria; incluso algunos afirmaron que nunca los habían usado. Después de realizar el análisis de cada fotografía con ellos, muchos rememoraron emotivos momentos con solo observar los objetos sonoros que portaban sus abuelos, padres o tíos y reconocieron la utilización de estos. Se incorporaron también los puntos de vista de los cuadrilleros novatos que dejar ver su interpretación del evento en la actualidad.

En esta investigación fue necesario tener en cuenta el rol que los artefactos e instrumentos desempeñan en las expresiones socioculturales. Durante el proceso fue indispensable recurrir a marcos conceptuales y metodológicos interdisciplinares. Como resultado se registraron algunos aspectos de la tradición oral de una región que se encuentra situada en los llanos orientales de Colombia. Para terminar y como parte del aprendizaje en el desarrollo de este proyecto, evocamos lo dicho por Mendivil (2016):

11 En algunos casos los instrumentos aún se encontraban en las viviendas de quienes participaron en el préstamo de fotografías. [los instrumentos no tienen origen], estos se constituyen a través de un eterno estado de transformaciones y lo que nosotros llamamos origen no es sino una debilitación arbitraria al interior de un continuo infinito. (p. 100).

Por tanto nuestra labor como historiadores no destapa verdades o reconstruye fidedignamente eventos pretéritos, sino que se deben proponer esquemas de interpretación para los datos históricos que poseemos y los nuevos que vamos recopilando. (p. 101).

\section{REFERENCIAS}

Aguirre, L. y Gómez Lozano, B. (2009). Informe final. Inventario de Patrimonio Cultural Inmaterial Municipio de San Martín (Meta). Bogotá, Colombia: inédito.

Barela, L.; Miguez, M. y García Conde, L. (2004). Algunos apuntes sobre historia oral. Buenos Aires, Argentina: Instituto histórico de la ciudad de Buenos Aires.

Bates, E. (2012). The social life of musical instruments. Ethnomusicology, 56 (3), 363-395.

Bermúdez, E. (1987). Música indígena Colombiana. Revista del Departamento de Antropología de la Universidad Nacional de Colombia, Manguare.

Dawe, K. (2001). People, objects, meaning. Recent work on the study and collection of musical instruments. The Galpin Society Journal, 54, 219-232.

Faraldo, J. M. (20001). Modernas e imaginadas. El nacionalismo como objeto de investigación histórica en las dos últimas décadas del siglo XX. Hispania, LX1/3 (209), 933-964. 
García Canclini, N. (2004). Culturas híbridas: estrategias para entrar y salir de la modernidad. México: Editorial Grijalbo.

Gétreau, F. (2009). Curt Sachs as a theorist for music museology. In Blazekovic, Z. and Dobbs Mackenzie, B. (Ed.). Music's Intellectual History: Founders, Followers $\mathcal{E}$ Fads. New York, USA: RILM.

Gómez, B. y Gómez, D. (2010). Plan Especial de Salvaguardia: San Martín de los Llanos (Meta). Bogotá, Colombia: Ministerio de Cultura. Grupo Patrimonio Inmaterial.

Herrera Muete, D. M. (2014). Re-encuentro con la esencia instrumental de las legendarias cuadrillas de San Martín de los llanos (Meta): historia viva de una tradición (trabajo de pregrado). Tunja, Colombia: Universidad Pedagógica y Tecnológica de Colombia.

Hortelano, L. (2003). Arqueomusicología: bases para el estudio de los artefactos sonoros prehistóricos. Valencia, España: Universitat de Valencia.

Hortelano, L. (2008). Arqueomusicología. Pautas para la sistematización de los artefactos sonoros. Archivo de Prehistoria Levantina, 27, 381-395.

Madrid, A. (2010). Música y nacionalismo en Latinoamérica. En Recasens Barberá, A. A tres bandas: mestizaje sincretismo e hibridación en el espacio sonoro iberoamericano. Madrid: Akal.

Madrid, A. L. (2008). Los sonidos de la nación moderna. La Habana, Cuba: Casa de las Américas .

Martínez, E. (2008/2011). San Juan de Arama: cuatro y medio siglos de historia. San Juan de Arama, Meta: Museum International $\mathrm{N}^{\circ}$ 221-222.

Martínez, F. (2001). El nacionalismo cosmopolita: la referencia europea en la construcción nacional en Colombia, 1845-1900. Bogotá, Colombia: Banco de la República/ Instituto francés de estudios andinos.

Melo Ángel, C. (2013). El documento musical en los procesos de salvaguardia del patrimonio musical colombiano. Bogotá, Colombia.

Mendivil, J. (2016). En contra de la música. Herramientas para pensar, comprender $y$ vivir las músicas. Buenos Aires, Argentina: Gourmet Musical.

Panofsky, E. (1994). Estudios sobre iconología [1939]. Alanza Editorial.

Pelinski, R. (2000). Invitación a la Etnomusicología. Quince fragmentos y un tango. Madrid: Ediciones Akal.

Pérez de Arce, J. y Gili, F. (2013). Clasificación Sachs-Hornbostel de instrumentos Musicales: una revisión y aplicación desde la perspectiva Americana. Revista Musical Chilena, 42-80.

Rueda Arenas, J. F. (2013). "Memoria histórica razonada". Una propuesta incluyente para las víctimas del conflicto armado interno colombiano. HistoReLo Revista de historia regional o local, 15-52.

Thompson, P. (2003 y 2004). Historia, memoria y pasado reciente. Anuario, 20, 15-34.

Vega, C. (1946). Los instrumentos Musicales Aborígenes y Criollos de la Argentina. Buenos Aires, Argentina: Centurión. 